\title{
Maksim-Maksim Kesantunan Berbahasa Tokoh dalam Novel Megat Karya Rida K Liamsi
}

\author{
Hadi Rumadi \\ Universitas Riau \\ Syafrial \\ Universitas Riau
}

\begin{abstract}
Abstrak
Latar belakang penelitian ini adalah fenomena kebahasaan tokoh dalam karya sastra berupa novel. Bahasa tokoh menarik untuk diteliti sebagai cerminan makna dan pesan cerita. Novel sebagai karya sastra memiliki peranan penting dalam merepresentatifkan nilai-nilai pendidikan, terutama kesantunan berbahasa. Rumusan penelitian adalah maksim-maksim apasajakah yang terdapat di novel Megat karya Rida K Liamsi. Tujuan penelitian yakni mendeskripsikan maksimmaksim apasajakah yang terdapat di novel Megat karya Rida K Liamsi. Manfaat penelitian sebagai media teoretis dan praktis. Teori yang digunakan adalah teori kesantunan berbahasa dan novel. Jenis penelitian adalah kualitatif. Objek penelitian yaitu novel Megat karya Rida K Liamsi. Metode yang digunakan adalah metode deskriptif analitis. Teknik pengumpulan data menerapkan teknik dokumentasi dan kepustakaan dalam menganalisis kata, frasa, klausa, atau kalimat bahasa yang mengungkapkan kesantunan berbahasa melalui paparan maksimmaksim kesantunan. Teknik analisis adalah identifikasi, deskripsi, pembahasan hasil dan penyimpulan. Hasil dari penelitian teridentifikasi maksim kebijaksanaan 35 data, permufakatan 14 data, penghargaan 13 data, kedermawanan 4 data, kesederhanaan 13 data, kesimpatian 9 data. Kesantunan berbahasa tokoh terimplementasi melalui maksim-maksim kesantunan, sehingga unsur estetis dan etis bahasa dalam bertindak tutur oleh tokoh sangat diutamakan.
\end{abstract}

Kata Kunci : Maksim, Kesantunan Berbahasa, Novel 
JOURNAL OF LANGUAGE, LITERATURE, AND TEACHING

Vol. 1 No. 3, December 2019, pp. 50 - 63

\begin{abstract}
The background of this research is the linguistic phenomenon of characters in literary works in the form of novels. The language of the interesting characters to be examined as a reflection of the meaning and message of the story. Novels as literary works have an important role in representing educational values, especially politeness in language. The research formula is the maxims of what is contained in the novel by Rida K Liamsi Megat. The purpose of this research is to describe the maxims of what is contained in the novel by Rida K Liamsi Megat. The benefits of research as a theoretical and practical media. The theory used is the politeness theory of language and novels. This type of research is qualitative. The object of research is Megat's novel by Rida K Liamsi. The method used is descriptive analytical method. Data collection techniques apply documentation and library techniques in analyzing words, phrases, clauses, or language sentences that express politeness in language through exposure to politeness maxims. Analysis techniques are the identification, description, discussion of results and conclusions. The results of the study identified a maximum of 35 data wisdom, 14 data agreements, 13 data awards, 4 data generosity, 13 data simplicity, 9 data conclusions. The politeness of the characters' language is implemented through politeness maxims, so that the aesthetic and ethical elements of language in acting by the characters are given priority.

Keywords: Maxim, Language Politeness, Novel
\end{abstract}




\section{Pendahuluan}

Secara sederhana, Horatius (dalam Sehandi, 2016:7) mengatakan bahwa sastra itu dulce et utie, artinya indah dan bermakna. Sastra sebagai sesuatu yang dipelajari atau sebagai pengalaman kemanusiaan dapat berfungsi sebagai bahan renungan dan refleksi kehidupan karena sastra bersifatkoekstensif dengan kehidupan, artinya sastra berdiri sejajar dengan hidup. Dalam kesustraan dapat ditemukan berbagai gubahan yang mengungkapkan nilai-nilai kehidupan, nilai- nilai kemanusiaan, nilai-nilai sosial budaya, diantaranya yang terdapat dalam puisi, prosa, dan drama. Pengungkapan nilai-nilai ini tergambar melalui alur dramatik salah satunya penggunaan bahasa yang digunakan oleh tokoh cerita.

Bahasa sebagai alat komunikasi yang melibatkan aspek kesantunan merupakan aspek penting dalam kehidupan guna menciptakan komunikasi yang baik antara penutur dengan lawan tutur. Etika kesantunan dalam berbahasa digunakan untuk menghargai baik orang lain maupun diri sendiri. Namun, dalam keseharian kita belum tentu bisa menerapkan aspek kesantunan dalam berbahasa dengan baik.

Etika berbahasa ini kerat kaitannya dengan norma-norma sosial dan sistem budaya yang berlaku dalam suatu masyarakat. Maka, etika berbahasa ini akan mengatur kita dalam hal :

a) apa yang harus dikatakan kepada seorang lawan tutur pada waktu dan keadaan tertentu berkenaan dengan status sosial dan budaya dalam masyarakat itu;

b) ragam bahasa yang paling wajar digunakan dalam waktu dan budaya tertentu;

c) kapan dan bagaimana kita menggunakan giliran berbicara kita menyela atau menginterupsi pembicaraan orang lain;

d) kapan kita harus diam, mendengar tuturan orang;

e) bagaimana kualitas suara kita keras, pelan, meninggi dan bagaimana sikap fisik kita di dalam berbicara itu.

Menurut Purwo (1994:87), ada beberapa ahli yang membedakan kesantunan berbahasa. Para ahli tersebut adalah Lakoff, Fraser, Brown dan Levinson serta Leech. Teori mereka itu pada dasarnya beranjak dari pengamatan yang sama, yaitu teori Grice bahwa didalam komunikasi yang sebenarmya, penutur tidak selalu mematuhi prinsip kerja yang sama, yang terdiri drari maksim-maksim kualitas, kuantitas, hubungan dengan cara 
itu. Perbedaannya antara lain terletak bgaimana pakar-pakar itu melihat wujud kesatuan kaidah. (Charlina dan

Mangatur, 2007;33). Dalam penelitian ini, fokus teori yang digunakan adalah teori Leech yang mengungkapkan maksim-maksim kesantunan yaitu sebagai sesuatu yang tidak bisa diremehkan. Karena menurut Leech, kesantunan yaitu menyangkut hubungan antara peserta komunikasi yaitu penutur dan pendengar. Maka penutur menggunakan kalimat dalam tuturannya dengan santun tanpa harus menyinggung pendengar. Adapun penggolongan maksim yaitu maksim kebijaksanaan, maksim kedermawanan, maksim penghargaan, ,aksim kesederhanaan, maksim pemufakatan, dan maksim kesimpatian. Menurut Elmustian dan Abdul Jalil (2006:19), Bahasa merupakan sistem semiotik (sistem tanda). Setiap tanda sebagai unsur bahasa mempunyai arti tertentu yang disepakati oleh masyarakat. Sistem bahasa dalam sastra mengandung dua aspek, yaitu:

1. Konsepsi, sebagai dasar pemahaman dunia nyata, mengarahkan sikap dan penafsiran kenyataan serta komunikasi.

2. Sistem kemaknaan yaitu mempunyai pengertian tertentu.

Dalam sastra, bahasa memiliki pengertian, bahasa tanpa pengertian bukanlah bahasa. Oleh karena itu, Sutardji Calzoum Bachri paling keras menentang pendapat ini. Lihat misalnya kredo sajak-sajak Sutardji dalam o Amuk Kapak (1981). Menurut Sutardji, puisi itu bebas dari penjajahan makna, dari beban ide dan merupakan penyimpangan dari sistem dan konvensi bahasa. Berdasarkan pemaparan latar belakang tersebut, penulis tertarik meneliti mengenai maksim-maksim kesantunan berbahasa tokoh dalam novel Megat karya Rida K Liamsi.

\section{Metode}

Jenis penelitian adalah kualitatif. Metode yaitu deskriptif analitis. Sesuai pendapat Ratna (2006:53) menyatakan bahwa deksriptif analitis adalah upaya mendeskripsikan atau menggambarkan fakta-fakta kemudian disusul dengan analisis. Sumber data merupakan satu novel berjudul Megat karya Rida K Liamsi. Novel ini sangat tebal dengan jumlah halaman 521. Warna kaver novel ini Hitam. Novel ini merupakan terbitan pertama pada tahun 2016 oleh PT Sagang Intermedia Pers. Objek penelitian ini adalah dialog yang ada di dalam novel Megat karya Rida K Liamsi. 
JOURNAL OF LANGUAGE, LITERATURE, AND TEACHING

Vol. 1 No. 3, December 2019, pp. 50 - 63

https://doi.org/10.35529/jllte.v1i3.50-63

Untuk memperoleh data penelitian, penulis menerapkan teknik dokumentasi dan kepustakaan dalam menganalisis kata, frasa, klausa, atau kalimat bahasa yang mengungkapkan kesantunan berbahasa berdasarkan maksim-maksim sesuai teori. Teknik analisis data dilakukan yaitu (1) mengklasifikasikan data kebahasaan (2) mendeskripsikan data sesuai metode. (3) membahas hasil penelitian, dan (4) penyimpulan, yaitu melakukan penarikan hasil penelitian berdasarkan temuan.

\section{Hasil}

Titik fokus penelitian ini adalah menentukan dan menyaring data penelitian yang berkaitan dengan unsur kebahasaan tokoh. Unsur kebahasaan ini meliputi unsur kesantunan berdasarkan maksim-maksim kesantunan yang sudah ditentukan. Berikut paparan hasil penelitian dalam tabel rekapitulasi hasil penelitian. Berdasarkan teori Leech, maka maksim-maksim kesantunan dapat terlihat pada tabel 1.2 berikut. 
JOURNAL OF LANGUAGE, LITERATURE, AND TEACHING

Vol. 1 No. 3, December 2019, pp. 50 - 63

https://doi.org/10.35529/jllte.v1i3.50-63

\begin{tabular}{|c|c|c|c|}
\hline No & Maksim & Jumlah & Total \\
\hline \multirow[t]{6}{*}{1} & Kebijaksanaan & 35 & \multirow{6}{*}{35} \\
\hline & Berpusat pada orang lain & 1 & \\
\hline & Menggunakan kalimat tanya untuk perintah & 3 & \\
\hline & $\begin{array}{l}\text { Menawarkan sesuatu yang menguntungkan } \\
\text { orang lain }\end{array}$ & 6 & \\
\hline & $\begin{array}{l}\text { Memberikan informasi yang tidak merugikan } \\
\text { orang lain }\end{array}$ & 23 & \\
\hline & $\begin{array}{l}\text { Kurangilah ungkapan yang menyiratkan hal- } \\
\text { hal yang merugikan orang lain }\end{array}$ & 2 & \\
\hline \multirow[t]{3}{*}{2} & Permufakatan & 14 & \multirow{3}{*}{14} \\
\hline & $\begin{array}{l}\text { Menghendaki diri dan orang lain sepakat, } \\
\text { setuju, atau cocok }\end{array}$ & 10 & \\
\hline & $\begin{array}{l}\text { Tidak selamanya harus setuju, menunjukkan } \\
\text { rasa tidak setuju disertai alasan }\end{array}$ & 4 & \\
\hline \multirow[t]{3}{*}{3} & Penghargaan & 13 & \multirow{3}{*}{13} \\
\hline & $\begin{array}{l}\text { Memberikan penghargaan secara tulus, seperti } \\
\text { mengagumi, memuji, menghormati, tidak } \\
\text { mengejek dan tidak merendahkan }\end{array}$ & 7 & \\
\hline & $\begin{array}{l}\text { Tidak mengatakan hal-hal yang tidak } \\
\text { menyenangkan orang lain }\end{array}$ & 6 & \\
\hline \multirow[t]{6}{*}{4} & Kedermawanan & 4 & \multirow{6}{*}{4} \\
\hline & Berpusat pada diri sendiri & 0 & \\
\hline & Menyiratkan kerugian diri sendiri & 1 & \\
\hline & $\begin{array}{l}\text { Memberi tawaran kepada orang lain seakan- } \\
\text { akan orang yang menawarkan tidak rugi }\end{array}$ & 1 & \\
\hline & $\begin{array}{l}\text { Memberikan bantuan sesuatu yang berupa } \\
\text { tindakan diri }\end{array}$ & 0 & \\
\hline & Membantu dengan memberikan saran & 2 & \\
\hline \multirow[t]{4}{*}{5} & Kesederhanaan & 13 & \multirow{4}{*}{14} \\
\hline & $\begin{array}{|lcc|}\text { Tidak menunjukkan } & \text { kelebihan } & \text { dan } \\
\text { kemampuan diri sendiri } & & \\
\end{array}$ & 5 & \\
\hline & $\begin{array}{l}\text { Menunjukkan kelemahan diri sendiri dan } \\
\text { bersikap rendah diri dengan pujian yang } \\
\text { diberikan }\end{array}$ & 2 & \\
\hline & Berusaha mengecam diri sendiri tetapi tidak & 7 & \\
\hline
\end{tabular}

\begin{tabular}{|c|l|c|c|}
\hline No. & \multicolumn{1}{|c|}{ Maksim } & Jumlah & Total \\
\hline & dilebih-lebihkan & & \\
\hline \multirow{2}{*}{6} & Kesimpatian & 9 & \multicolumn{1}{|c|}{} \\
\cline { 2 - 4 }
\end{tabular}


JOURNAL OF LANGUAGE, LITERATURE, AND TEACHING

Vol. 1 No. 3, December 2019, pp. 50 - 63

\begin{tabular}{|l|l|l|}
\hline $\begin{array}{l}\text { Ikut merasakan apa yang dirasakan orang lain } \\
\text { Ucapan bela sungkawa terhadap kemalangan } \\
\text { orang lain }\end{array}$ & 0 & \multirow{2}{*}{$\mathbf{9}$} \\
\cline { 1 - 2 } $\begin{array}{l}\text { Ucapan selamat terhadap suatu hal yang } \\
\text { menyenangkan }\end{array}$ & 0 & $\mathbf{8 9}$ \\
\hline
\end{tabular}

Data dalam tabel 1.2 menunjukkan jumlah data yang berbeda-beda. Temuan ini berdasarkan 300 dialog yang dianalisis berdasarkan maksim kesantunan pada setiap dialog, terdapat 89 data maksim kesantunan diantaranya, 35 data maksim kebijaksanaan, 14 data maksim permufakatan, 13 maksim penghargaan, 4 maksim kedermawanan, 14 maksim kesederhanaan, dan 9 maksim kesimpatian. Langkah selanjutnya adalah mendeskripsikan hasil penelitian. Peneliti hanya mengambil sampel dari data, mengingat data yang ditemukan berkaitan dengan masalah yang sama.

\section{Pembahasan}

Sesuai dengan metode yang digunakan dalam penelitian ini yaitu metode deskrpsi, maka langkah berikutnya yang akan dilakukan adalah pendeskripsian hasil penelitian berdasarkan data yang sudah dipaparkan pada tabel 1.2. pendeskripsian sangat penting dilakukan guna mengungkapkan interpretasi maksim-maksim yang terkandung di dalam dialog tokoh. Berikut paparan deskrpsi data penelitian.

1. Maksim Kebijaksanaan.

a. Berpusat pada orang lain Siang hari, di dalam rumah wah ijan sedang berdiskusi dengan Megat. "Hemm dah handal kau tu? Dah boleh jadi pedekar macam Ayah kau?" (242).

Data di atas mendeskripsikan keadaan bahwa wah ijan mengatakan kepada megat, seolah megat merupakan seorang yang hebat seperti ayahnya dahulu yang menjadi seorang jawara pada masanya. Berpusat pada orang lain 
ditandai dengan kata Ayah Kau. Kata tersebut menjadikan patokan wah ijan untuk menggambarkan kehidupan megat sekarang.

b. Menggunakan kalimat tanya untuk perintah

Malam hari di dalam kamar hotel mereka berdiskusi mengenai hubungan mereka dalam keadaan santai "Bagaimana Dinda urus, urusan dengan keluarga Dinda ya.?. Dengan segala resiko. Kita sudah sama memilih....," (63)

Data di atas mendeskripsikan keadaan, bahwa dinda memerintakahkan megat untuk segera mengurus keseriusan hubungan merekaberdua dan membicarakan kepada kedua belah pihak keluarga mereka. menggunakan kalimat tanya untuk perintah ditandai dengan kalimat Bagaimana Dinda urus urusan dengan kelurga dinda ya?. Tuturan tersebut ditujukan kepada megat agar segera mengurus keperluan mengenai kelanjutan hubungan mereka, karena pada saat itu mereka menikah sirih secara diam-diam.

c. Menawarkan sesuatu yang menguntungkan orang lain

Siang hari di dalam istana, semua orang mendengarkan pembicaraan mereka yang nampak tegang dalam suasana hening. "Beta hendak berjalan kaki saja kepintu gerbang istana menunggu Sultan, sebelum kemesjid. Sunnahkan berjalan agak jauh ke mesjid untuk fardu jum 'at?’.(3)3

Data di atas mendeskripsikan bahwa terjadi diskusi antara Bendahara Tun Abdul Jalil dengan Megat ketika merekahendakpergi ke masjid untuk melaksanakan salat jumat. Kalimat menawarkan sesuatu yang menguntungkan orang lain ditandai dengan Sunnahkan berjalan agak jauh ke mesjid untuk fardu jum 'at?".(3)3.

d. Memberikan informasi yang tidak merugikan orang lain

Siang hari di dalam istana, semua orang mendengarkan permintaan bentara. "Bawa dua tiga pengawal".(3)4

Data di atas mendeskripsikan percakapan antara Bentara dengan orang yang berada dalam istana. Bentara merupakan salah seorang yang di segani oleh banyak orang di Istana. Memberikan informasi yang tidak merugikan orang lain 
JOURNAL OF LANGUAGE, LITERATURE, AND TEACHING

Vol. 1 No. 3, December 2019, pp. 50 - 63

https://doi.org/10.35529/jllte.v1i3.50-63

ditandai pada kalimat "Bawa dua tiga pengawal". Tuturan ditujukan bendahara kepada orang-orang yang ada di sekitar istana. Pada saat itu Bendahara Tun Abdul Jalil hendak pergi shalat Jumat bersama Megat dengan berjalan kaki.

e. Kurangilah ungkapan yang menyiratkan hal-hal yang merugikan orang lain

Siang hari di meja makan, Megat berbicara serius kepada Adinda. "Hemm, peristiwa pembunuhan Sultan Mahmud II, sorry saya pakai istilah Mahmud II seperti kata buku-buku sejarah, karena di masa kemaharajaan Melayu itu, kan ada banyak Mahmud, jadi agak susah membeda-bedakan Mahmud yang mana satu, meski Mahmud-Mahmud itu tidak hidup di waktu yang sama dan di kerajaan yang sama..." (98)

Data di atas mendeskripsikan sejarah harus dikaji secara detail agar tidak menimbulkan berbagai penafsiran, salah sedikit saja bisa bergeser jauh dari kisah sesungguhnya. Penamaan tokoh sejarah yang berpengaruh dalam sejarah juga harus hati-hati agar tidak menimbulkan gagal paham antar sesama.

\section{Maksim Penghargaan}

Memberikan penghargaan secara tulus, seperti mengagumi, memuji, menghormati, tidak mengejek dan tidak merendahkan Siang hari di dekat anak tangga istana. Bendahara coba menasehati Megat atas keinginan kuatnya untuk memindahkan tahta Johor ke Bentan. "Beta tahu kepedihan dan kemurkaan Laksamana... tapi seperti beta semalam, Sultan bukan orang sembarangan. Selain banyak pengawal, dia juga berisi. Apakah tidak perlu dipikirkan lagi, dan mengatur cara yang lebih selamat dan tidak meluru seorang diri??"(5)

Data di atas mendeskripsikan Bendahara Tun Abdul Jalil sedang berdiskusi dengan Megat. Sultan adalah orang tertinggi di kerajaan pada saat itu. Sultan juga bukan orang yang sembarangan dan sangat bijaksana.

Memberikan penghargaan secara tulus, seperti mengagumi, memuji, menghormati, tidak mengejek dan tidak merendahkan ditandai dengan dialog “Sultan bukan orang sembarangan”. Tuturan ditujukan Bendahara kepada Megat untuk memberitahu bahwa Sultan orang yang hebat.

b. Tidak mengatakan hal-hal yang tidak menyenangkan orang lain 
JOURNAL OF LANGUAGE, LITERATURE, AND TEACHING

Vol. 1 No. 3, December 2019, pp. 50 - 63

https://doi.org/10.35529/jllte.v1i3.50-63

Siang hari di gerai Suka Cita. Percakapan antara Tengku Adinda dan Megat tentang sejarah kerjaan Melayu. "Hanya tinggal islam sebagai perekat dan mengubur semua adat istiadat etnis yang tersisa. Tragis? Dan abang Megat ni, yang hapal betul jejak penting sejarah kerajaan Melayu di kawasan semenanjung dan sekitarnya ini ya, dan sangat kritis, meskipun bukan sejarawan. Dimana abang berpijak?"(151-152)

Data di atas mendeskripsikan cerita sejarah Melayu yang sangat penting bagi penelitian Dinda. Dinda dan Megat selalu mengadakan diskusi kapan saja dan dimana saja. Tempat favorit mereka untuk berdiskusi adalah di gerai Suka Cita.

Tidak mengatakan hal-hal yang tidak menyenangkan orang lain ditandai dengan dialog "Hanya tinggal islam sebagai perekat dan mengubur semua adat istiadat etnis yang tersisa. Tragis? Dan abang Megat ni, yang hapal betul jejak penting sejarah kerajaan Melayu di kawasan semenanjung dan sekitarnya ini ya, dan sangat kritis, meskipun bukan sejarawan.".

Tuturan ditujukan Megat kepada Dinda. Megat menjadi narasumber yang kredibel bagi Dinda. informasi yang di beri oleh Megat semuanya penting untuk penulisan Dinda. karena Megat tidak mengatakan hal-hal yang menyinggung dirinya atau orang lain.

\section{Maksim Kesederhanaan}

a. Tidak menunjukkan kelebihan dan kemampuan diri sendiri

Hotel di dini hari perasaan senang memulai pembicaraan dengan perempuan itu "O ya? Bagus nama tu. Melankolik. Kakak Hafsah. Tapi tak pakai Tengku, tak pakai Raja. Tak pakai Wan. Hafsah saja...," (45)

Data di atas mendeskripsikan percakapan antara Dinda dengan seorang perempuan yang baru dia kenal sewaktu di hotel. Pertemuan mereka menambah daftar teman yang Dinda kenal selain Megat Ismail.

b. Menunjukkan kelemahan diri sendiri dan bersikap rendah diri dengan pujian yang diberikan

Di kursi saat pagi menjelang siang dekat penjual buku permbicaraan serius antara Megat dan aDinda. "Jangan tanya umurlah. Pemali kata orang tuatua... Hahaha... Pokoknya sudah bukan anak muda lagi...” (94)

Data di atas mendeskripsikan pembicaraan serius antara Megat dengan Dinda di dekat toko penjual buku. Pembicaraan mereka mengenai informasi- 
informasi seputar ilmu pengetahuan mereka tentang kebudayaan Melayu. Di selasela keseriusan mereka isi dengan beberapa bumbu candaan untuk mencairkan suasana.

c. Berusaha mengecam diri sendiri tetapi tidak dilebih-lebihkan ramai dan riuh ketika siang itu di gerai suka cita saat obrolannya dengan ADinda yang sekilas berdebat. "Tak ada niat kurang ajar. Cuma ingin melalui hari agar dahi tak selalu berkerut, dan cepat tua..., "Itulah kalau jauh dari rumah...,"(157)

Data di atas mendeskripsikan suasana yang riuh di gerai suka cita saat jam makan siang. Orang-orang ramai berkunjung saat istirahat jam makan siang di gerai tersebut. Megat dan Dinda memperdebatkan suatu hal yang berupa candaan.

Berusaha mengecam diri sendiri tetapi tidak dilebih-lebihkan ditandai dengan dialog "Tak ada niat kurang ajar. Cuma ingin melalui hari agar dahi tak selalu berkerut, dan cepat tua..., "Itulah kalau jauh dari rumah...," Tuturan ditujukan Megat kepada Dinda. Megat mengakui dirinya yang sudah tua dan kulit mulai berkerut, maka dari itu Megat mengurangi hal-hal yang membuatnya menambah kerutan dan penuaan pada dirinya.

\section{Maksim Pemufakatan}

a. Menghendaki diri dan orang lain sepakat, setuju atau cocok

Siang hari menjelang sholat jumat, di dalam istana, Megat berdebat sambil menahan amarah kepada bendahara. "Seperti yang telah kita rundingkan semalam, jika Datuk hendak menjadi Sultan, inilah saatnya. Patik mau mendurhaka saat ini, tidak boleh tidak."(4)

Data di atas mendeskripsikan perdebatan Megat dengan Bendahara. Megat sudah tersulut emosi, karena Bendahara tidak menghiraukan perkataannya, Bendahara selalu berdalih dan mengalihkan pembicaraan mereka. Menghendaki diri dan orang lain sepakat, setuju atau cocok ditandai dengan dialog “jika Datuk hendak menjadi Sultan, inilah saatnya. Patik mau mendurhaka saat ini, tidak boleh tidak." Tuturan ditujukan Megat kepada Bendahara. Megat mendesak. Bendahara untuk melakukan pergerakan menggantikan patik yang mendurhaka. Banyak yang menyetujui pergerakan itu pada saat mereka berunding kemarin. 
JOURNAL OF LANGUAGE, LITERATURE, AND TEACHING

Vol. 1 No. 3, December 2019, pp. 50 - 63

https://doi.org/10.35529/jllte.v1i3.50-63

\section{Maksim Kesimpatian}

a. Ikut merasakan apa yang dirasakan orang lain

Gerai suka cita siang itu obrolan Megat dan Adinda, Adinda mulai berkelekar. "Andaikan Megat Seri Rama tidak mendurhaka, tak sampailah abang ke sini ya...,(154)

Data di atas mendeskripsikan di gerai suka cita siang itu Megat dan Dinda sedang Makan siang. Ketika makan juga mereka mnyempatkan membahas tentang cerita Megat terdahulu. Cerita juga di campuri sedikit candaan untuk menghibur diri.

Ikut merasakan apa yang dirasakan orang lain ditandai dengan dilaog "Andaikan Megat Seri Rama tidak mendurhaka, tak sampailah abang ke sini ya...,". Tuturan ditujukan Dinda kepada Megat. Megat berfikir bahwa benar juga yang dikatakan Dinda., walaupun Dinda hanya bercanda pada saat itu, tetapi Dinda juga merasakan apa yang Megat rasakan atas mendurhakanya Megat Sri Rama.

\section{Maksim Kedermawanan}

a. Menyiratkan kerugian diri sendiri

Malam hari di Hotel. Dialog antara Megat dan Adinda. "Kita kan sudah dewasa. Kalau mereka menolak menerimanya, ya, kita memilih cara hidup sendiri. Tak ada yang salah. Abang pun kalau harus bercerai dengan isteri abang, ya, abang lakukan...," (62).

Data di atas mendeskripsikan kedekatan Megat dengan Dinda sudah melebihi batas. Megat ternyata jatuh hati pada Dinda, Dinda yang awalnya hanya berniat menjadikan Megat sebagai pembimbing tesis, kini mereka terikat suatu hubungan terlarang, karena Megat sudah memiliki istri dan 2 orang anak.

Menyiratkan kerugian diri sendiri ditandai dalam dialog "Tak ada yang salah. Abang pun kalau harus bercerai dengan isteri abang, ya, abang lakukan.”

Tuturan ditujukan Megat kepada Dinda. Megat berusaha meyakinkan Dinda agar mau menikah dengan Megat. Sesungguhnya Megat itu mengalami kerugian yang sangat besar dan tidak ternilai. Megat malah akan menceraikan istrinya untuk 
JOURNAL OF LANGUAGE, LITERATURE, AND TEACHING

Vol. 1 No. 3, December 2019, pp. 50 - 63

https://doi.org/10.35529/jllte.v1i3.50-63

Dinda. Megat menjadi buta dan bodoh karena bersikap seperti itu.

b. Memberi tawaran kepada orang lain seakan-akan orang yang menawarkan tidak rugi

Siang hari disekitar meja makan. Dialog antara Megat dan Tengku Adinda. "Ini ada buku tentang sejarah Siak, mungkin Dinda belum punya, karena baru tahun lalu diterbitkan.” (116)

Data di atas mendeskripsikan Megat menunjukkan salah satu karyanya kepada Dinda. Megat memang seorang penulis yang hebat pada saat itu. Pengetahuannya akan kebudayaan Riau dan Kepulauan Riau menjadi nilai lebih untuk Megat.

c. Memberikan bantuan sesuatu yang berupa tindakan diri

Dini hari didepan pintu kamar ibunya. Adinda khawatir dengan yang terjadi pada Megat. "Mak 'kan' dah tahu Bang Megat 'kan? Dia orang baik. Dia sekarang perlu pertolongan. Dinda khawatir terjadi sesuatu...," (36) 4.

Data di atas mendeskripsikan Dinda dan Megat kini sudah berada di rumah masing-masing. Acara seminar sudah berlalu, hanya menyisakan kenangan. Mereka juga masih sangat sering berkomunikasi lewat pesan elektronik (e-mail). Kabar tidak menyenangkan datang, Megat jatuh sakit dan sedang di rawat di rumah sakit. Megat terindikasi penyakit paru-paru, karena pengaruh rokok yang sangat bahaya.

d. Membantu dengan memberikan saran

Dini hari dirumah, dialog antara ibu dan Adinda. "Tapi kau kan sudah kenal keluarganya. Sudah pernah makan minum di sana, apa salahnya kalau memang mustahak. Mereka kan sudah juga pernah ke rumah kita. Tapi, ya sudah. Terpulang kau-lah. Mak nak sembahyang subuhlah dulu ya...." (53)

Data di atas mendeskripsikan Emak Dinda dan Dinda sedang berdiskusi tengah malam di rumah. Diskusi tersebut mengenai tentang Megat. Membantu dengan memberikan saran ditandai dengan dialog "Tapi kau kan sudah kenal keluarganya. Sudah pernah makan minum di sana, apa salahnya kalau memang 
JOURNAL OF LANGUAGE, LITERATURE, AND TEACHING

Vol. 1 No. 3, December 2019, pp. 50 - 63

mustahak." Tuturan ditujukan Emak Dinda kepada Dinda. Emak Dinda menyarakan pada Dinda agar bertemu dengan keluarga Megat.

Berdasarkan hasil penelitian, persoalan maksim kesantunan berbahasa yang paling banyak ditemukan adalah maksim kebijaksanaan. Temuan ini mendeskripsikan bahwa tokoh-tokoh dalam novel Megat karya Rida K Liamsi sangat bijaksana dalam mengutarakan suatu maksud kepada tokoh lain. Kebijaksanaa dalam berbahasa mencerminkan unsur kesantunan berbahasa.

Dialog-dialog yang diucapkan oleh tokoh novel megat mendeskripsikan bahwa kesantunan berbahasa memuat unsur etis dan estetis. Hal ini terlihat adanya temuan pendayagunaan gaya bahasa. Gaya bahasa adalah cara penutur menyampaikan maksud dan perasaan dengan cara tersendiri, dan ini adalah ciri khas bahasa sastra yang puitis. Dialog adalah unsur penting dalam memahami alur cerita novel. Dialog menjadi sentral poin bagi pembaca dalam menentukan dan memahami pesan yang dikandung dalam cerita.

\section{Daftar Pustaka}

Charlina dan Mangatur Sinaga. (2007). Pragmatik. Pekanbaru: Cendikia Insani. Chaer, Abdul. (2010). Kesantunan Berbahasa. Jakarta : Rineka Cipta. Elmustian dan Abdul Jalil. 2006. Teori Sastra. Pekanbaru: Unri Press.

Purwo, Bambang Kaswanti. (1990). Pragmatik dan Pengajaran Bahasa. Yogyakarta: Kanisius.

Ratna, Nyoman Kutha. (2006). Teori, Metode, dan Teknik Penelitian Sastra. Yogyakarta: Pustaka Pelajar.

Sehandi, Yohanes. (2016). Mengenal 25 Teori Sastra. Yogyakarta: Ombak. Liamsi, Rida K. (2016). Megat. Pekanbaru: PT Sagang Intermedia Pers. 